\title{
EDUCAÇÃO AMBIENTAL NA AMAZÔNIA EM PERÍODO DE PANDEMIA
}

\author{
Wander de Jesus Barboza Duarte ${ }^{1}$
}

Resumo: A Amazônia é uma região de superlativos, com dimensões continentais, que se espalha por todos os países do norte da América do Sul. Seus múltiplos matizes culturais, ambientais e biológicos são apenas parcialmente conhecidos, fato que limita de forma marcante as necessárias intervenções físicas da região. É preciso considerar que mais de vinte e cinco milhões de pessoas vivem na parte brasileira da Amazônia e são os verdadeiros responsáveis por sua conservação, e, em parte por sua revelação nos tempos atuais. $\mathrm{O}$ mundo vem experimentando mudanças ambientais significativas, com reflexos diversos, ora acentuando a magnitude de eventos naturais, ora reduzindo seus efeitos. A presente pesquisa busca desenvolver elementos que contribuam para entender as causas e consequências dos eventos climáticos extremos na Amazônia em período de pandemia Covid-19 e verificar possíveis causas e consequências das queimadas e seca na Amazônia por meio de análise robusta dos dados disponíveis, partindo de uma ampla revisão bibliográfica, para identificar os fatores críticos, propondo uma reflexão sobre essas preocupações que devem ser consideradas nos processos decisórios relacionados à conservação, mitigação e adaptação aos efeitos das queimadas, das mudanças climáticas, as quais devem se acentuar nos tempos vindouros.

Palavras-chave: Queimadas; Pandemia Covid-19; Meio Ambiente.

Abstract: The Amazon is a region of superlatives, with continental dimensions, which spreads across all the countries of northern South America. Its multiple cultural, environmental and biological nuances are only partially known, a fact that markedly limits the necessary physical interventions of the region. It is necessary to consider that more than twenty-five million people live in the Brazilian part of the Amazon and are the real responsible for its conservation, and, in part, for its revelation in the current times. The world has been experiencing significant environmental changes, with different reflexes, sometimes accentuating the magnitude of natural events, sometimes reducing their effects. This research seeks to develop elements that contribute to understand the causes and consequences of extreme climatic events in the Amazon in a pandemic Covid-19 period and to verify possible causes and consequences of fires and drought in the Amazon through robust analysis of the available data, starting from of a wide bibliographic review, to identify the critical factors, proposing a reflection on these concerns that must be considered in the decision-making processes related to the conservation, mitigation and adaptation to the effects of the fires, of the climatic changes, which should be accentuated in the coming times.

Keywords: Burnings; Covid-19 Pandemic; Environment.

${ }^{1}$ Faculdade de Ciências Sociais e Aplicadas de Marabá-PA. E-mail: duartewanderdejesus@gmail.com. 


\section{Introdução}

Quando se fala em Educação Ambiental, percebe-se que o assunto ganhou visibilidade com relevância na questão de ameaças globais, como a erosão da camada de ozônio e o aquecimento do planeta. A questão ambi ental está no rol das grandes questões internacionais. Dessa forma, a Educação Ambiental deve contribuir para a preparação de pessoas que obtenham a compreensão que o uso predatório da natureza, as queimadas e a poluição do meio ambiente trazem consequências negativas para a sociedade.

Hoje em dia é comum acreditar que a questão ambiental é uma invenção do século XX. De fato, o tema só ganhou projeção a partir dos anos 1960, década que testemunhou os primeiros esforços de chamar a atenção do mundo para as consequências da exploração irrestrita dos recursos naturais. De acordo com os especialistas, a humanidade chegou a um momento decisivo de sua história. Se a economia mundial continuar crescendo no mesmo ritmo da última década, o planeta não suportará a demanda por recursos naturais já em 2050. Isto é, em poucas décadas, o homem enfrentará a escassez de itens indispensáveis à sua existência. A não ser que algo seja feito a respeito. Nesse contexto, de que forma desmatamentos, secas e incêndios podem provocar mudanças climáticas e impactar a Amazônia?

$\mathrm{Na}$ Amazônia, pode-se dizer que a vida, em todas as suas dimensões, depende dos pulsos de cheia e vazante, e esses parecem ser sensíveis às mudanças ambientais originadas em outros cantos do planeta. Por essas e outras razões, entender as causas e consequências dos eventos climáticos extremos na Amazônia é de fundamental importância.

O objetivo geral desta pesquisa é apresentar contribuições que relacionam eventos extremos com impactos nas áreas de terra firme da Amazônia. E os objetivos específicos se apresentam em entender os impactos da seca na floresta e a frequência com que as queimadas ocorrem durante as secas, bem como a severidade dos incêndios florestais no período de pandemia Covid-19.

Para o presente artigo foi utilizada como metodologia a pesquisa bibliográfica, através de referencial teórico e artigos científicos já publicados, na plataforma SCIELO (Scientific Electronic Libray OnLine), no viés qualitativo, como também a utilização da metodologia do trabalho científico.

\section{Amazônia}

Segundo Alfredini (2014) o Brasil possui mais de $8.500 \mathrm{~km}$ de linha costeira, considerando os recortes litorâneos. Dezessete Estados da Federação compõem essa linha de costa, contando com portos marítimos, estuarinos e lagunares, pelos quais se movimenta a quase totalidade do comércio exterior do país (navegação de longo curso), além da navegação de cabotagem entre os portos nacionais. 
Aos mais de 60 principais portos comerciais marítimos brasileiros, agregam-se mais de 60 portos fluviais ou terminais hidroviários, compondo um conjunto de mais de uma centena de polos multimodais de transporte públicos e privados.

\section{Identificação da Amazônia}

De acordo com Gonçalves (2010) a Amazônia (Figura 1) cumpre um importante papel na imagem que os brasileiros fazem de si próprios e de seu país. Normalmente se diz que o Brasil é o país do futuro. Nessa imagem, está subjacente a ideia de que o Brasil é um país de dimensões continentais, portador de imensos recursos naturais que nos garantiriam um futuro promissor. Nessa perspectiva a Amazônia, que corresponde a cerca de 54\% do território brasileiro, seria um imenso reservatório de recursos naturais sendo, por isso, vista como o futuro do Brasil.

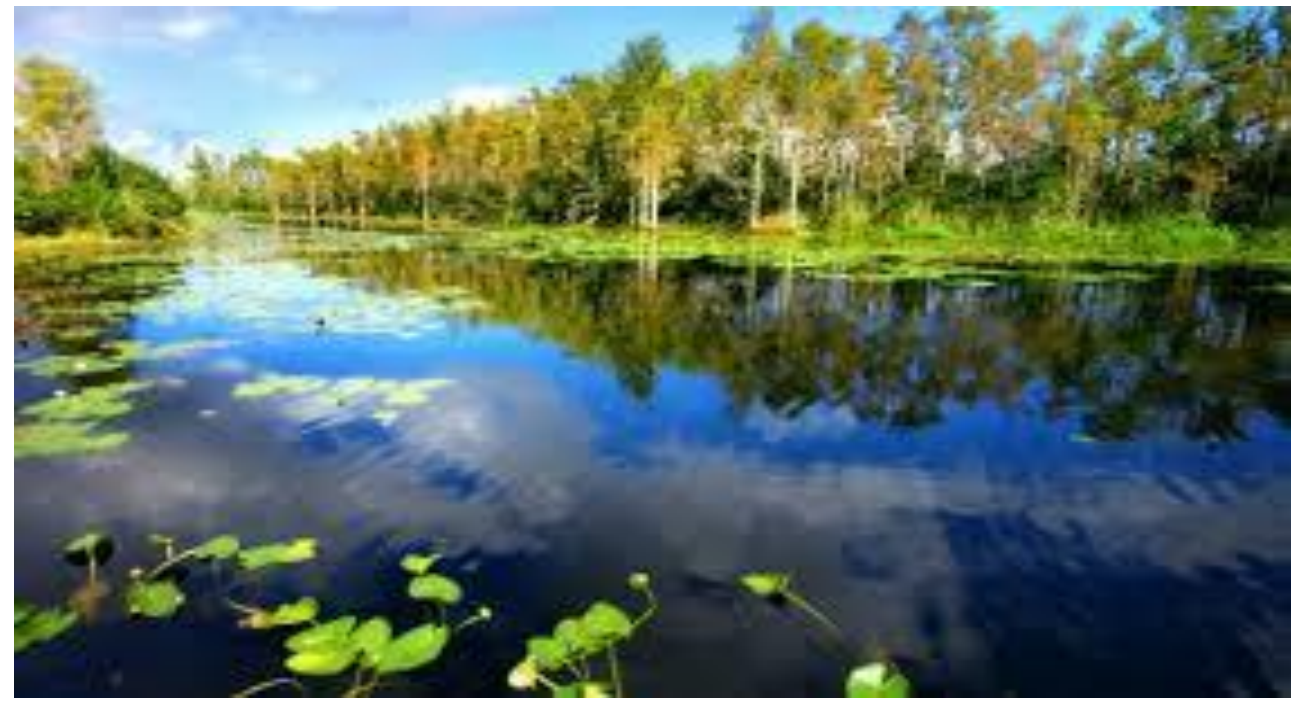

Figura 1: Recursos Naturais da Amazônia.

Fonte: Meio Ambiente - Cultura Mix (2020).

Segundo Gonçalves (2010) a Amazônia está associada a uma imagem de uma área de aproximadamente 7,5 milhões de $\mathrm{km}^{2}$, localizada na porção centro-oriental da América do Sul (Figura 2), cortada pelo Equador terrestre, com um clima quente e úmido, coberta por uma densa floresta tropical úmida, banhada por uma intrincada e extensa bacia hidrográfica que tem o rio Solimões-Amazonas como eixo principal, habitada por uma população rarefeita constituída basicamente por populações indígenas ou caboclas que abriga riquezas naturais incalculáveis. 


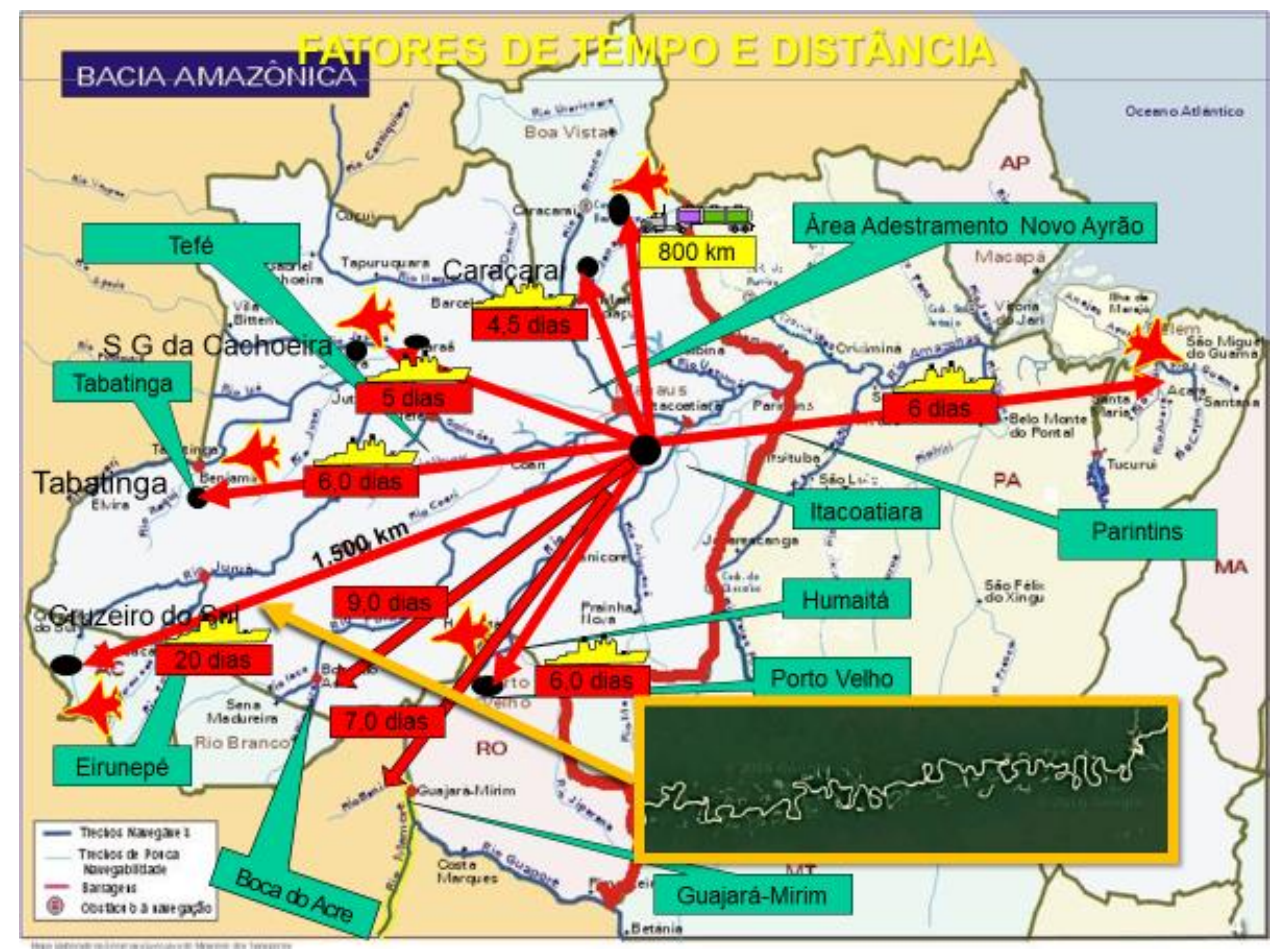

Figura 2: Bacia Amazônica.

Fonte: Portal Neo Mondo (2020).

A importância da Amazônia serviu para o governo nacional barganhar a implantação da Companhia Siderúrgica Nacional, base do processo de industrialização por substituição de importações e do projeto militar nacionalista de construir uma indústria de base capaz de gerar as condições materiais e tecnológicas necessárias para que as Forças Armadas desempenhassem seu papel de defesa da integridade territorial do país. Relata Gonçalves (2010) que ainda durante a Segunda Guerra Mundial o governo brasileiro volta a dar demonstração da velha tutela das elites nacionais não amazônicas com relação à Amazônia. Cria novos territórios Federais como o Amapá,

Rio Branco (atual Roraima) e Guaporé (atual Rondônia), amputando espaço aos antigos Estados do Pará, Amazonas e Mato Grosso, e mantendo ainda o Acre na condição de território. Colocam-se assim, sob a administração direta do governo federal, amplas parcelas dos territórios dos estados amazônicos.

É o reconhecimento tácito da frágil inserção social e econômica da sociedade que se propôs a colonizar a região, mesmo transcorridos mais de três séculos de ocupação.

A Amazônia Verde, de acordo com Becker (2008) adquiriu valor simbólico para o futuro da humanidade, pelo seu potencial e pela oportunidade que passou a representar para o mundo. Sua contribuição para o clima global é hoje objeto de grande preocupação. Com um olhar geopolítico sobre a Amazônia têm-se como ambição mostrar que o futuro desejado é possível. 
Esclarece ainda, Becker (2008) que os governos da América do Sul entraram em acordo em 2000 , de que era necessário realizar ações conjuntas para impulsionar o processo de integração política, social e econômica sulamericana. Desse entendimento surgiu a IIRSA (Iniciativa para a Integração da Infraestrutura Regional Sul-Americana), o que tem por objetivo promover o desenvolvimento da infraestrutura de transporte (Figura 3), energia e telecomunicações, sob uma visão regional, procurando uma integração física dos doze países da América do Sul e visando alcançar um padrão de desenvolvimento territorial equitativo e sustentável. (IIRSA, 2007 apud BECKER, 2008, p. 88).

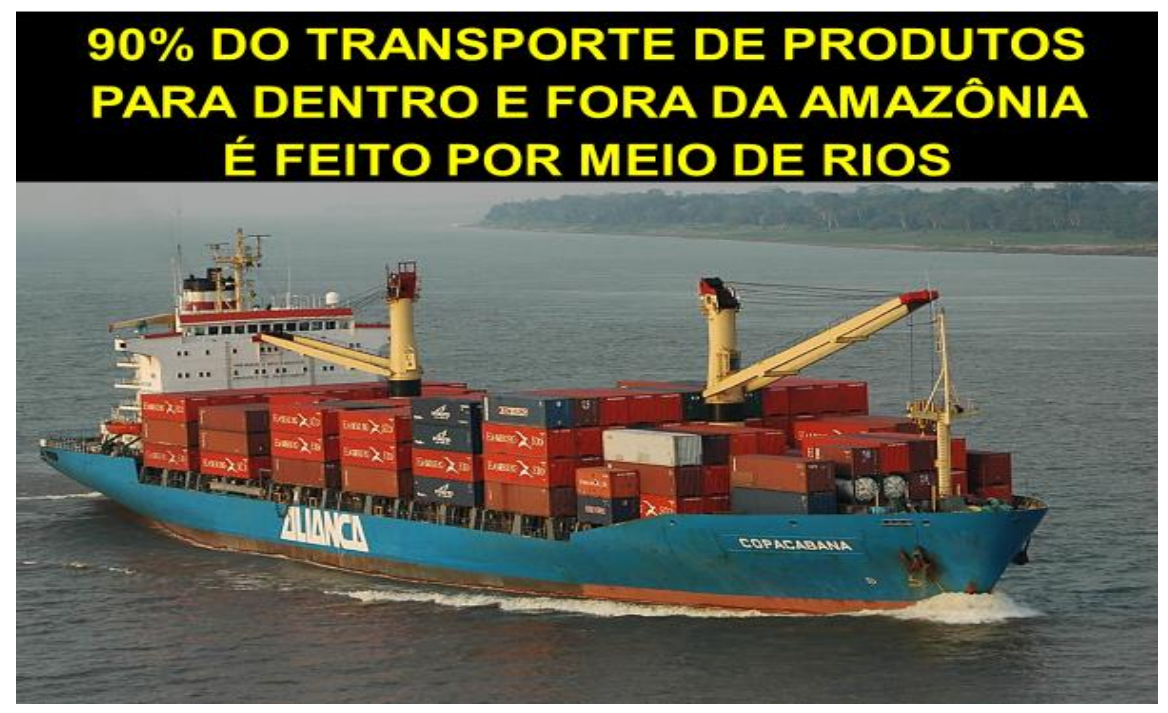

Figura 3: Transporte de produtos.

Fonte: Calenda.org (2020).

As populações amazônicas necessitam de uma logística mais eficiente. Nesse sentido, um dos elementos-chave é multimodalidade, que pode significar redução de custos, maior eficiência, maior velocidade, e melhor adequação às especificidades ambientais da região.

Três modalidades são básicas para a região: fluvial, aérea e de informação. Os rios da Amazônia podem se tornar uma grande vantagem competitiva, pois o transporte hidroviário é a melhor opção em termos de custos e eficiência energética. Para isso, é necessário que haja investimentos em tecnologia na área de engenharia.

Segundo Becker (2008) a bacia Amazônica é a mais extensa bacia hidrográfica do planeta (Figura 4), formada por um emaranhado de $25.000 \mathrm{~km}$ de rios navegáveis, distribuídos em $6.925 .674 \mathrm{~km}^{2}$, dos quais $3.836 .520 \mathrm{~km}^{2}$ em território brasileiro. É o amplo sistema fluvial que unifica os vários ecossistemas florestais contíguos que compõem a Amazônia Sul-americana a maior floresta tropical do mundo formada por um complexo ecológico transnacional. 




Figura 4: Amazônia Verde.

Fonte: Portal Neo Mondo (2020) e Calenda.org (2020).

Explica-nos ainda Becker (2008) que as redes convencionais são as modalidades usuais, naturais e/ou com tecnologia convencional: fluvial, aérea e rodoviária. Nesse sentido, destaca-se na Amazônia a modalidade hidrográfica. Os seus rios sempre foram as estradas naturais que permitiram e orientaram 0 processo de ocupação até meados do século XX. Existem milhares de quilômetros de vias navegáveis na bacia Amazônica. Alguns são apenas flutuáveis, outros oferecem condições para uma navegação rudimentar, e os principais rios são francamente navegáveis.

Algum desses como o Amazonas/Solimões e o Madeira, apresentam elementos de balizamento e sinalização que os caracterizam como hidrovias (Figura 5). A rede hidrográfica da região forma um sistema hierarquizado de transporte, com uma gigantesca rede de rios menores, o que permite a navegação de pequenas embarcações e garante capilaridade ao transporte hidroviário. Além da navegabilidade, existem nas cidades ribeirinhas amazônicas, dezenas de pequenas estruturas portuárias que são fundamentais para o transporte de pessoas e as relações comerciais e políticas dessas cidades. 


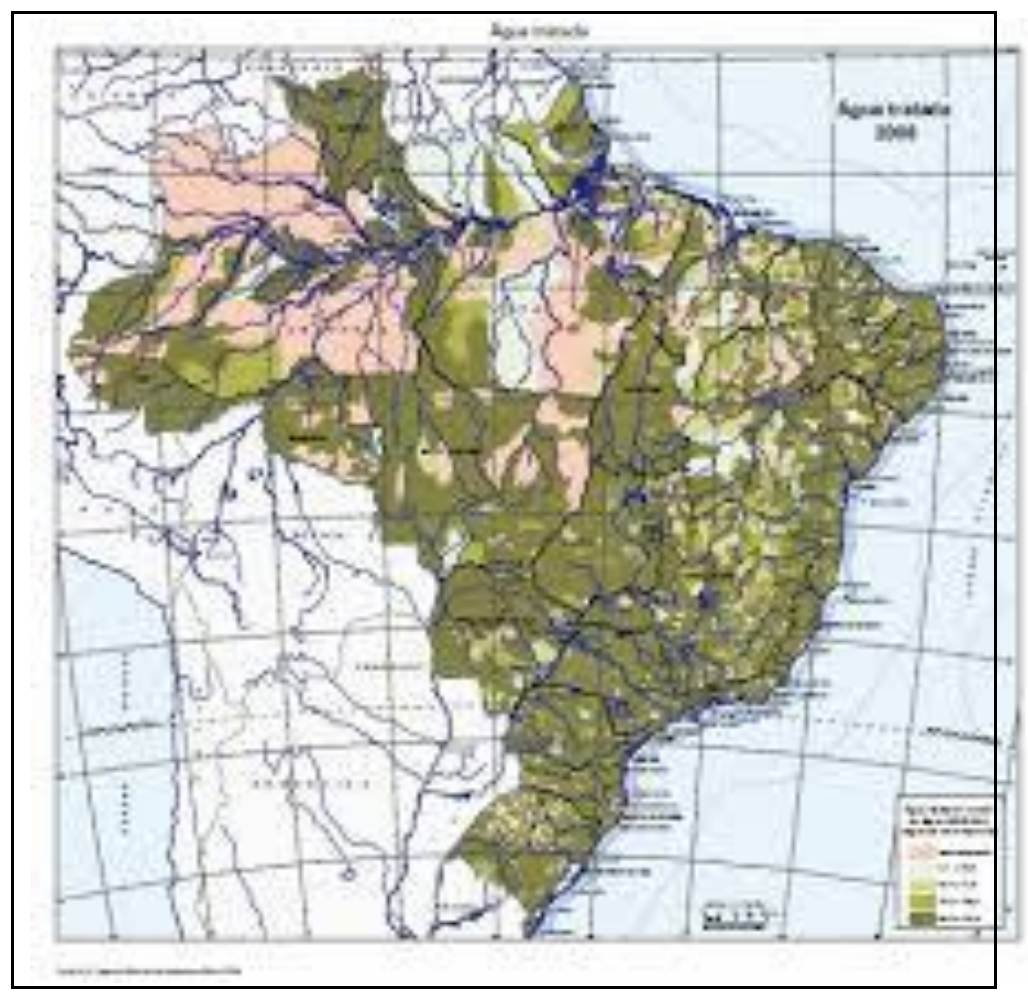

Figura 5: Rede Hidrográfica da Amazônia.

Fonte: Revistas USP (2020).

\section{Capacidades e limitações das hidrovias, na região norte do país;}

Os rios Tapajós/Teles Pires e os rios Araguaia/Tocantins (Figura 6), são potenciais hidrovias para o transporte de grãos e para a integração da região central do Brasil. A operação e a implantação de uma hidrovia, também exigem pesquisas hidrográficas e engenharia naval. É necessário compreender o regime hidrológico dos rios e monitorar constantemente a profundidade e a localização do canal de navegação (Figura 7), do contrário, é grande o risco de encalhe.

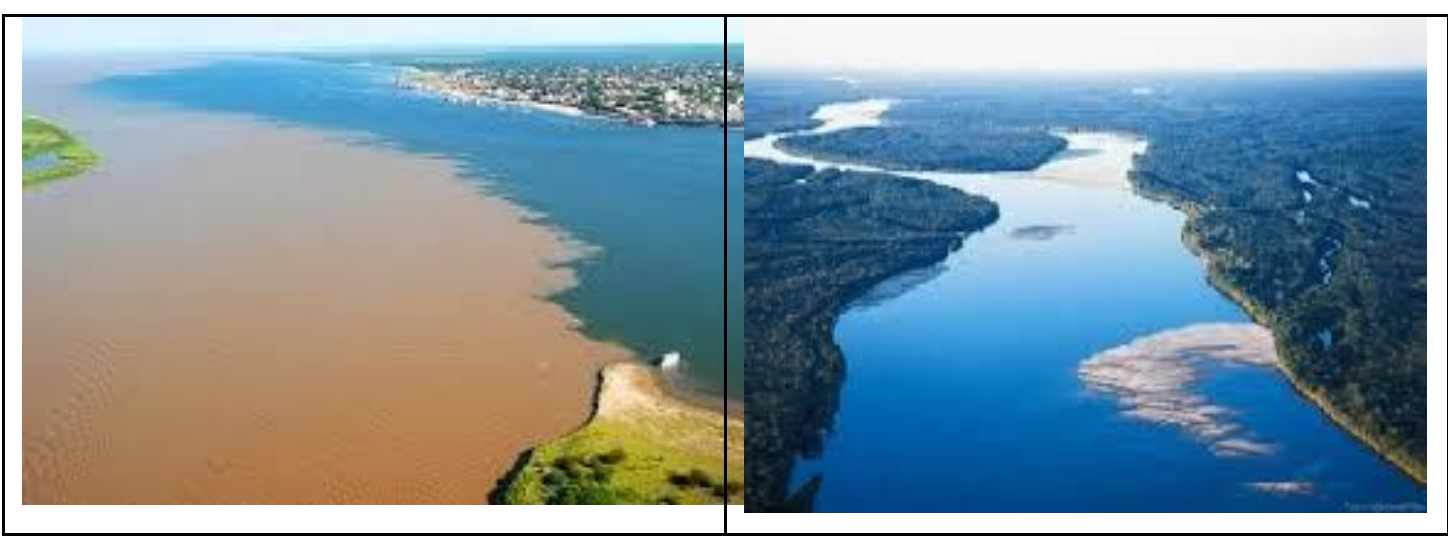

Figura 6:Tapajós/Teles Pires e rios Araguaia/Tocantins.

Fonte: TripAdvisor (2020) e Meio ambiente-cultura mix (2020). 


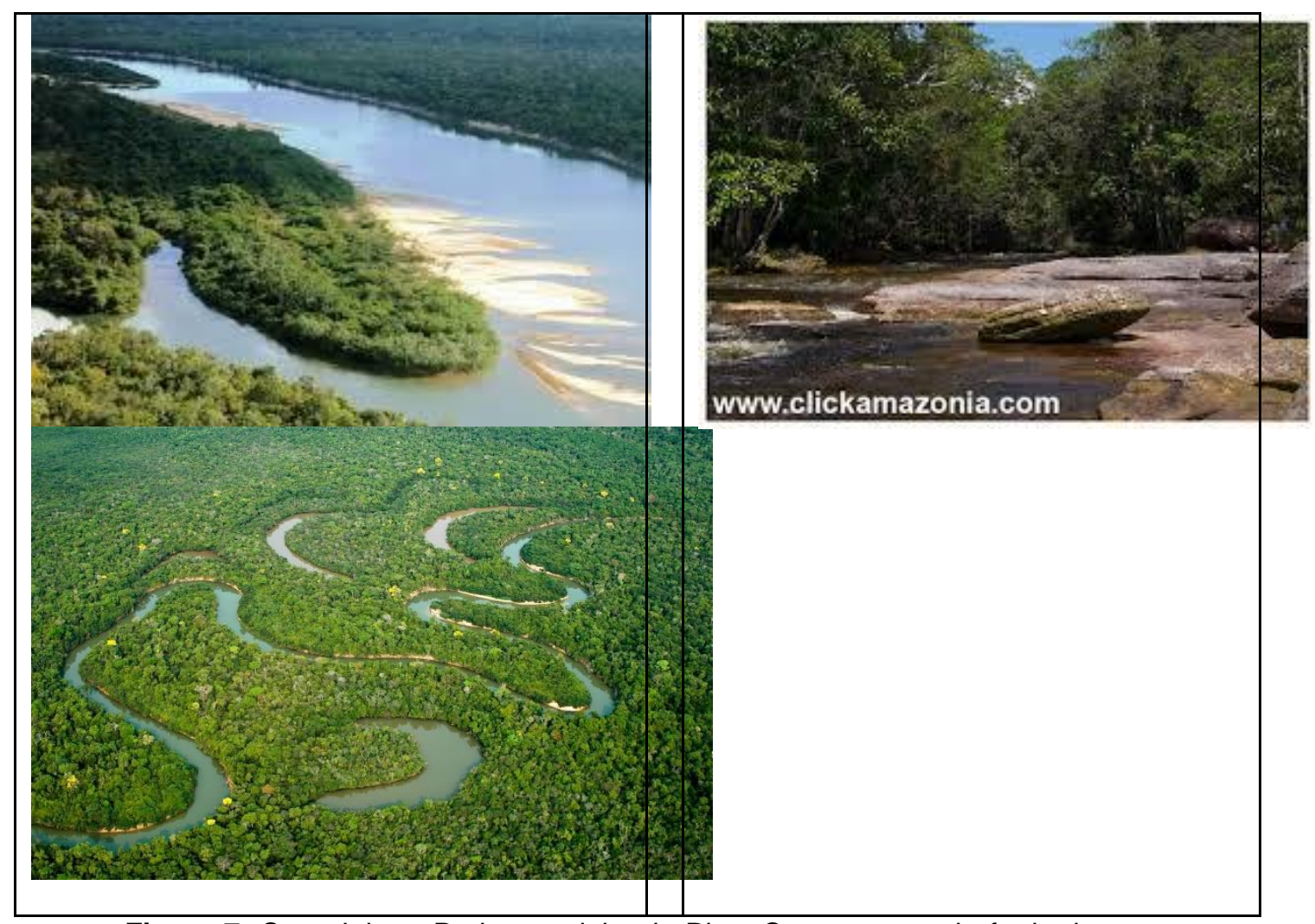

Figura 7: Corredeiras, Pedras no leito do Rio e Curvas com raio fechado.

Fonte: Amazônia News (2020).

\section{Secas na bacia amazônica}

Conforme relatado por Borma (2013) na história recente da bacia amazônica, grandes secas têm sido detectadas, entre elas citam-se 1912, 1925, 1964, 1980, 1983, 1997/98, 2005 e 2010. Em geral, suas causas têm sido associadas à variabilidade interanual nos padrões de circulação e temperatura de superfície do mar nos oceanos Pacífico e Atlântico tropical, decorrentes, principalmente de oscilações natu rais.

Porém, novos estudos já começam a discutir a possibilidade de influência humana nas secas, seja por meio dos impactos do desmatamento regional ou do efeito das queimadas, que tendem a alongar a estação seca e a atrasar o início da estação chuvosa na Amazônia.

O projeto de Educação Ambiental no período de pandemia propõe exatamente a implantação de uma nova logística. 


\section{Desenvolvimento econômico e logística para Amazônia}

O nível de desenvolvimento econômico dos países tem alta correlação com a qualidade de sua infraestrutura e o Brasil, há muitos anos, apresenta nível de investimentos bastante aquém da necessidade. Há lacunas importantes a serem fechadas em praticamente todos os setores, o que aumenta o chamado custo Brasil e, em consequência, o preço dos produtos produzidos no país, o que prejudica o nível de competitividade.

Redes de infraestruturas críticas, de energia, petróleo, gás, saneamento, finanças, logística e comunicações fazem parte dos serviços essenciais ao funcionamento de cidades, regiões, nações e continentes. Preservar sua integridade física e funcional é requisito para a qualidade de vida e segurança das sociedades modernas e um fator crítico de sucesso da geopolítica, estratégia militar e segurança de todas as nações.

A formação de blocos coesos de países, por razões geopolíticas, econômicas, militares ou religiosas, promove a interligação e extensão das redes de infraestrutura além das fronteiras nacionais. A possibilidade de ataques terroristas ou militares transforma essas redes em alvos e objetivos estratégicos prioritários à defesa nacional. A ocorrência de grandes desligamentos ou apagões nesses sistemas têm gerado questionamentos da sociedade sobre sua segurança e responsabilidades.

De acordo com Siqueira (2014) a natureza dos produtos e insumos, bem como o meio de transporte utilizado, definem as características das redes logísticas, e sua interdependência das demais redes sociotécnicas.

As funções logísticas (Figura 8) são compreendidas em: suprimento; manutenção; salvamento; saúde; recursos humanos; transporte e engenharia.

\section{FUNÇÃO LOGÍSTICA MANUTENÇÃO}

Capacidade do Dique Seco da NBVC

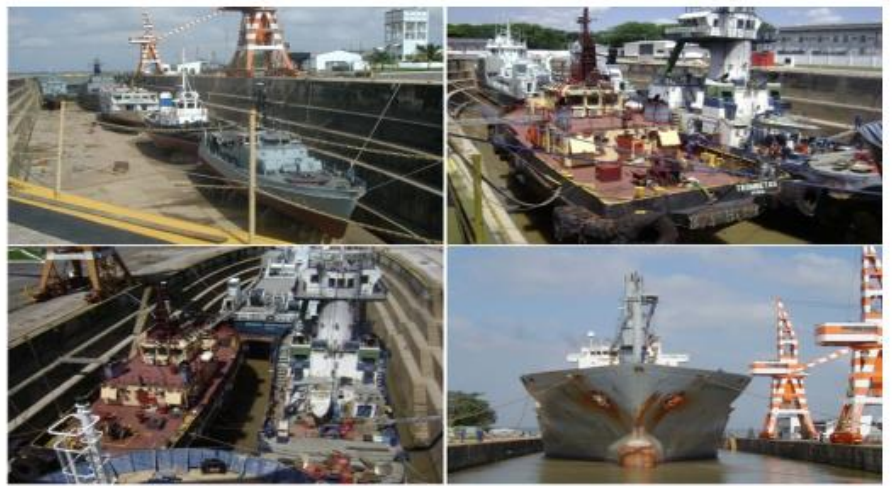

Figura 8: Função Logística de Manutenção

Fonte: Logisticando (logística e distribuição, 2020). 
A função logística Salvamento a atividade de Salvamento (Figura 9) tem como propósito o combate a incêndios, desencalhe ou reflutuação de meios, reboque, desobstrução de portos e rios, e está direcionada especificamente

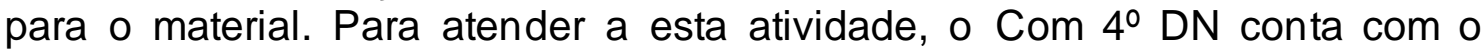
RbAM Alte Guilhem, que atua no desencalhe, reboque e Combate a Incêndios por ser especialmente equipado para prestar estes típicos auxílios.

\section{SALVAGUARDA DA VIDA HUMANA}
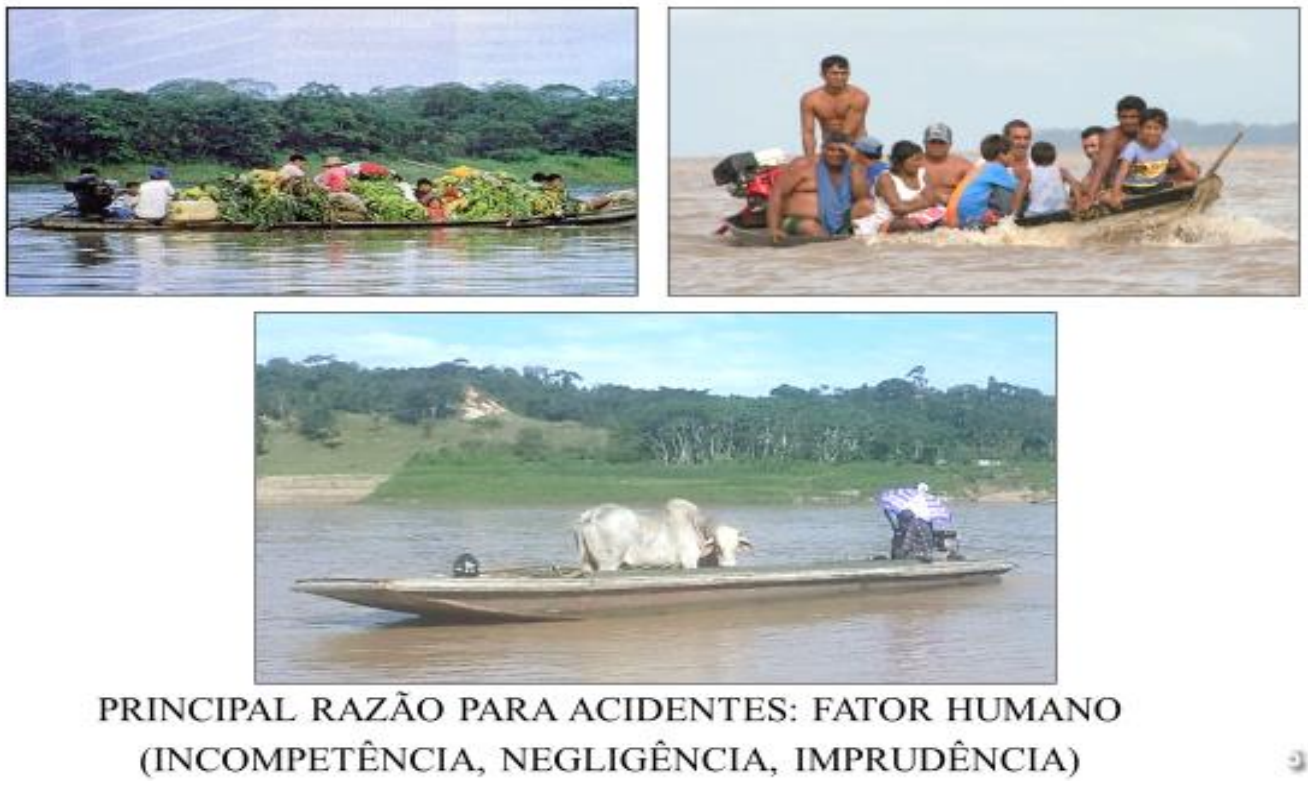

Figura 9: Salvaguarda da vida humana.

Fonte: Logisticando (logística e distribuição, 2020).

A missão do SALVAMAR (Figura 10) é prestar socorro ao navegante em apuros, atendendo as emergências relacionadas à salvaguarda da vida humana no mar.

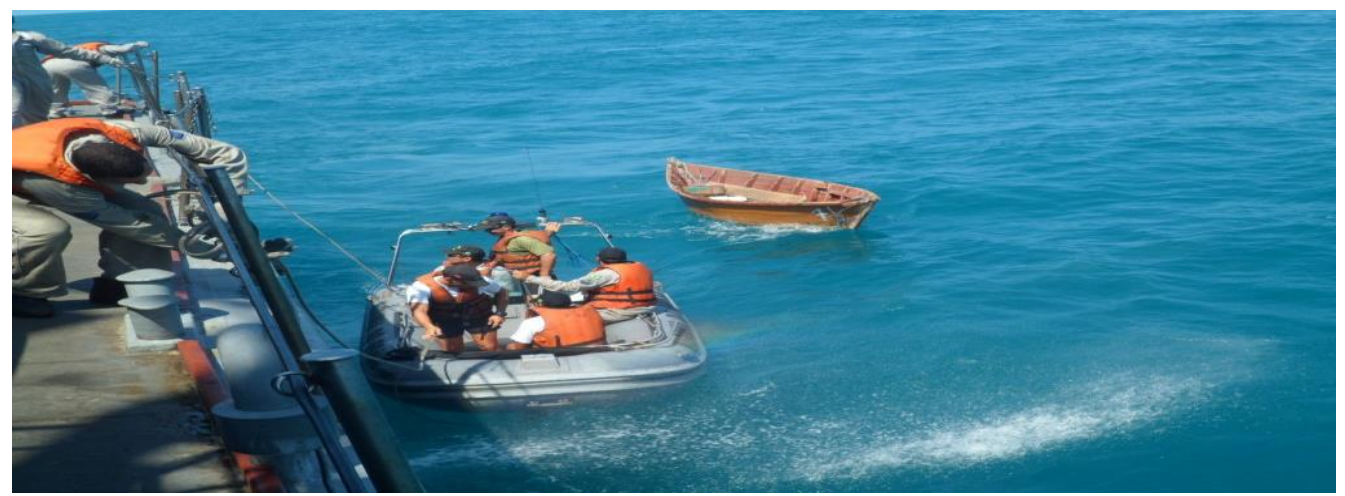

Figura 10: Salvamar

Fonte: Logisticando (logística e distribuição, 2020). 
A função logística saúde prevê e provê recursos específicos aos efetivos empregados pela Marinha do Brasil. Tem como propósito o de contribuir para a seleção, conservação e melhoria das condições de saúde do pessoal civil e militar.

O CIABA é a Organização Militar responsável por formar, aperfeiçoar, atualizar e adestrar o pessoal das categorias profissionais da Marinha Mercante e demais atividades correlatadas.

A função logística transporte (Figura 11) o 4ํㅡㄹ DN possui apenas um Navio Auxiliar Pará, que pode transportar cerca de 218 fuzileiros navais. Situação semelhante é encontrada no transporte de carga, aqui generalizado entre peças de artilharia, munição e suprimentos, por não se dispor de meios que possam atender a esses serviços da Função Logística de Transporte. As restrições apontadas, podem ser sanadas com o deslocamento de Navios da Esquadra para a Região ou mesmo por meio da mobilização de embarcações que operam na Amazônia.

\section{FUNÇÃO LOGÍSTICA TRANSPORTE}



Figura 11 Função Logística de Transporte

Fonte: Logisticando (logística e distribuição, 2020)

Os itens transportados podem ser pessoas, insumos ou bens manufaturados, ou mesmo resíduos industriais e residenciais, incluindo nesta classe as redes de coleta e processamento de lixo domiciliar e de limpeza urbana. Os meios de transporte podem ser heterogêneos, combinando vias terrestres, aéreas e aquáticas interligadas por terminais de integração intermodais.

Com o objetivo de coletar, armazenar, transportar e distribuir itens e produtos em uma determinada região ou empreendimento. Nestas redes, a interrupção dos elementos ocorre pela interdição de vias de transporte ou pontos de fornecimento, coleta, transbordo, consumo e distribuição sob o comando de uma autoridade local ou remota, ou por um evento da natureza. 
Além de insumos e produtos industriais, redes logísticas também podem transportar lixo e pessoas. Isto inclui as redes coletoras de lixos e resíduos urbanos, e os meios de transporte aeroportuário, ferroviário, dutoviário e hidroviário, incluindo marítimo, fluvial e os transportes de massa, como trens metropolitanos e metrôs.

Dependendo dos produtos transportados, serão necessários, água, energia, óleo ou gás para produzir, processar, conservar, armazenar e transportar os produtos aos consumidores finais, inversamente, redes logísticas (Figura 12) poderão transportar estes mesmos insumos (água, energia, óleo ou gás) entre produtos e consumidores caracterizando a interdependência entre as redes. De forma análoga, redes logísticas também podem representar cadeias produtivas e de suprimento (suply chain), nas indústrias de manufatura, e redes de alimentação na agricultura e pecuária também consideradas redes logística e de infraestrutura críticas.

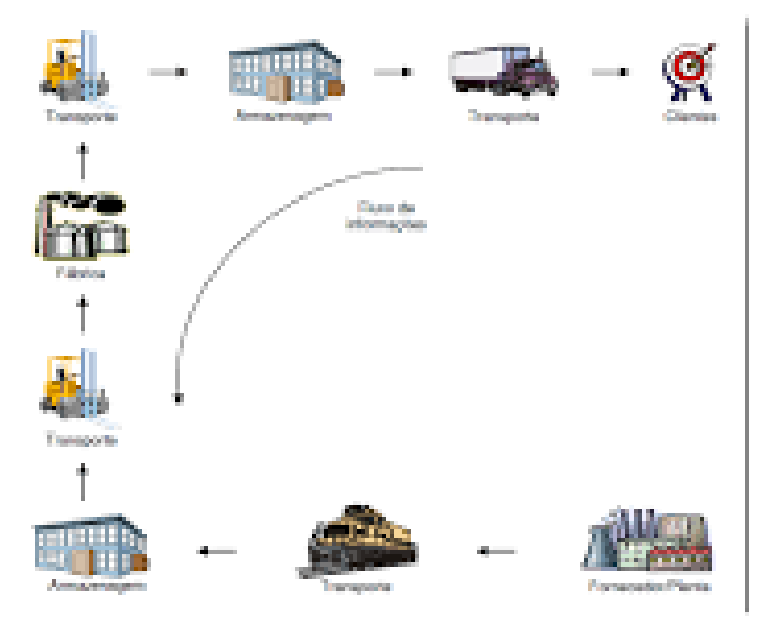

Figura 12 Logística de distribuição

Fonte: Logisticando (logística e distribuição, 2020)

Nessa rede, nota-se o fluxo de produtos nas vias de transporte, entre fornecedores e armazéns de estocagem e distribuição. A extrema carência de recursos de toda ordem, aliada às grandes distâncias dos principais centros produtores do país, evidenciam que uma das mais significativas dificuldades da Região Amazônica para uma Força Naval: a inexistência de apoio logístico fora de sua base.

A partir dos anos 2000, a expansão econômica impulsionada pelo crescimento do mercado interno e pela força do agronegócio, pressionou ainda mais a já debilitada rede logística brasileira, bastante defasada em relação à dos países líderes em desempenho da infraestrutura de transportes. 
De acordo com Lobão (2017) países com economias consideradas em desenvolvimento têm como característica adotarem modelos de crescimento econômico voltados para o sucesso na inserção externa, por meio de suas capacidades e estruturas produtivas. Os incentivos às exportações se tornam essenciais para uma maior dinâmica de expansão da produção doméstica, evitando uma produção interna pouca diversificada. Nesse sentido, deve-se atentar aos níveis de inserção externa que as regiões propiciam ao país, no intuito de elevar a produção e diversificar seus produtos para o consumo externo.

Com o intenso processo de abertura econômica verificada no início da década de 1990 no Brasil, acirrou-se a competitividade dos produtos nacionais no mercado externo, por meio de pesquisa em novas tecnologias e do estímulo a produtividade, que se estendem conjuntamente com o Plano Real. Esse cenário revelou uma industrialização brasileira com baixo grau de dinamismo na comercialização de produtos manufaturados, característico de políticas industriais protecionistas adotadas nas décadas passadas.

A partir dessas constatações e do entendimento de que o Brasil apresenta uma relação diferenciada dentro das suas macrorregiões com 0 setor externo, seja devido às especificidades econômicas regionais ou mesmo decorrente da sua extensão territorial, passa-se aqui a buscar compreender como a região Norte do Brasil tem se comportado e contribuído, no decorrer dos últimos anos, no comércio exterior brasileiro.

A tendência nacional do aumento de exportações de produtos básicos em detrimento daqueles com maior valor agregado é seguida pela Região Norte, vale ressaltar que, dentro do contexto da Região Norte, a Zona Franca de Manaus representa uma política de desenvolvimento regional que permite a importação de mercadorias com isenção ou redução de impostos, inclusive, compreende uma área de livre comércio que abrange os Estados do Acre, Amazonas, Rondônia e Roraima, bem como as cidades de Macapá e Santana no Amapá (SUPERINTENDÊNCIA DA ZONA FRANCA DE MANAUS [SUFRAMA], 2016).

A Zona Franca de Manaus foi criada com o intuito de fortalecer um centro industrial, comercial e agropecuário, dentro do contexto e interior amazônico (BRASIL, 1967). Fica no Estado do Amazonas o grande polo industrial beneficiado com os incentivos fiscais especiais, localizado na cidade de Manaus, o que tem explicado o Amazonas ser o único Estado da Região Norte a apresentar saldo negativo no balanço de pagamentos. Isto também justifica o alto grau de importação de produtos manufaturados, uma vez que a Zona Franca de Manaus importa muitos componentes eletrônicos intermediários para a industrialização, para posterior montagem em produtos finais como eletroeletrônicos, eletrodomésticos, dentre outros (SUFRAMA, 2016). 


\section{Amazônia Azul}

O projeto de levantamento da plataforma continental é hoje o único projeto que agrega território e riquezas ao Brasil, tendo, portanto, uma importância incomensurável, essa é a Amazônia Azul, que como a Amazônia Verde é um patrimônio Nacional, um outro Brasil no mar.

O mar sempre teve uma enorme importância para o Brasil, pelo mar chegaram os colonizadores portugueses, e a partir do seu litoral, o país começou ser explorado e povoado. Pouco se conhece sobre o importante significado estratégico e econômico desse mar.

O Brasil possui uma política nacional para os recursos do mar, cuja finalidade é orientar a utilização, exploração e aproveitamento dos recursos vivos, minerais e energéticos das águas jurisdicionais, de forma racional e sustentável, para o desenvolvimento socioeconômico do Brasil. Para coordenar a execução desta política foi criada em 1974, a Comissão Interministerial para os Recursos do Mar a ser coordenada pela autoridade marítima, função que passou a ser exercida pelo comandante da Marinha do Brasil.

Assim, a Marinha do Brasil, além de proteger as águas jurisdicionais brasileiras, passou a ser a maior responsável pela execução da política nacional para os recursos do mar, uma enorme responsabilidade diretamente proporcional ao tamanho da imensa Amazônia Azul, um verdadeiro mundo novo ainda pouco conhecido. Dessa forma, existe o enfoque de quatro vertentes a serem estudadas, que são os seus aspectos mais relevantes, a vertente econômica, a vertente ambiental, a vertente científica e a vertente da soberania.

$\mathrm{Na}$ vertente econômica as riquezas e as atividades mais importantes desta região são os seguintes: o tran sporte marítimo, mais de $95 \%$ do comércio exterior brasileiro, é transportado pelo mar, as importações e exportações brasileiras, transportadas por via marítima, somam mais de quatrocentos bilhões de dólares ao ano, o petróleo é uma das grandes riquezas da Amazônia Azul, no mar o Brasil prospecta cerca de $90 \%$ do seu petróleo, no ano de 2013, foram extraídos setecentos e trinta e oito milhões de barris de petróleo do mar, mas, muito mais ainda está para ser descoberto e explorado, na área do pré-sal uma porção do subsolo que se encontra sob uma camada de sal situada a alguns quilômetros abaixo do leito do mar, em profundidade de até dois mil metros de lâmina d'água e até seis mil metros de profundidade no subsolo, três campos de petróleo já foram descobertos, podendo fazer com que as reservas brasileiras comprovadas de petróleo que eram de 15,7 bilhões de barris de petróleo aumentassem para 43 bilhões de barris, fazendo do Brasil uma das de maiores reservas de petróleo do mundo. (in site, AMAZÔNIA AZUL, 2020).

A exploração da região do pré-sal já foi iniciada e em janeiro de 2014 foi atingida a marca de 390 mil barris de petróleo extraídos por dia dessa área. 
Essa quantidade irá aumentar gradativamente conforme forem chegando as novas plataformas de exploração de petróleo, encomendadas pelas empresas que atuarão nessa região, 92\% do petróleo extraído do mar no Brasil vem da empresa estatal brasileira Petrobrás, estima-se que existam ainda outras reservas de petróleo não descobertas na área do pré-sal com o volume total de até 80 bilhões de barris.

Sobre a vertente ambiental, a Marinha do Brasil atua nesta vertente, fiscalizando as águas para prevenir a poluição e impedir a pesca ilegal, porém, essa ação isolada ainda é muito pequena em vista dos problemas ambientais a serem enfrentados pelo país e da imensa área a ser fiscalizada. No que diz respeito a vertente científica, coordenada pela Comissão Interministerial para os recursos do mar, busca compreender a totalidade das riquezas contidas na Amazônia Azul para poder melhor explorá-la, respeitando a vertente ambiental e gerando subsídios para ela.

A vertente da soberania envolve a proteção da Amazônia Azul, sua importância é fundamental, pois é ela que irá garantir que todas as outras três vertentes possam ser executadas e que o Brasil possa explorar as riquezas de suas águas jurisdicionais com segurança. A soberania da Amazônia Azul é garantida pela Marinha do Brasil, através de ações da Patrulha Naval e de presença militar no mar.

Além da patrulha naval, como atividade subsidiária, o ComGptPatNavN contribui diretamente com a sociedade em Ações Cívico Sociais, nas quais grande esforço logístico é empreendido no atendimento a populações ribeirinhas carentes de serviços básicos de saúde, destacando-se dificuldade de acesso a determinadas regiões, transporte de profissionais de saúde e de medicamentos.

A zona econômica exclusiva brasileira não possui muros e nem obstáculos que possam impedir ou afugentar possíveis invasores que venham a explorar o Patrimônio do Brasil, somente uma força naval moderna e bem equipada com um tamanho proporcional a essa imensa área a ser protegida, pode dar conta deste trabalho.

Para garantir a soberania no mar, a Marinha do Brasil está desenvolvendo importantes projetos estratégicos que permitirão a ela dispor de meios navais, aeronavais e de fuzileiros navais que assegurem a necessária proteção desse outro Brasil no mar, com a ampliação do comércio marítimo e a crescente importância comercial e estratégica que as regiões norte e nordeste do país passaram a ter para o cenário nacional, é necessária a criação de uma segunda esquadra e de uma segunda força de fuzileiros da esquadra que possam assumir a responsabilidade pela segurança e proteção desta região, principalmente a do rio Amazonas. Para isso, será construído na região, em local a ser ainda determinado, um complexo naval, constituído de uma base naval, de uma base de fuzileiros navais, de uma base aérea naval, de uma base de abastecimento e de organizações militares de apoio par que possa abrigar o comando chefe da segunda esquadra e o comando da segunda força

Revbea, São Paulo, V. 16, № 4: 398-418, 2021. 
de fuzileiros da esquadra. Isso permitirá eficiente defesa e segurança do setor norte e nordeste, além de aumentar a capacidade de dissuasão da Marinha do Brasil como um todo.

A Marinha do Brasil, está buscando o desenvolvimento de todas as vertentes da Amazônia Azul, trabalhando para a consolidação de uma força naval equilibrada e balanceada com o tamanho proporcional do imenso espaço oceânico, e da crescente relevância política estratégica que o Brasil ganhou no cenário internacional. O Brasil tem uma grande relação de dependência com o seu mar e se fosse privado do seu livre uso e da extração dos recursos nele existentes, enfrentaria uma crise sem precedentes, capaz de paralisar o país rapidamente. Dessa forma, para que isso não ocorra, a fiscalização e a proteção das suas águas jurisdicionais são fundamentais.

\section{Desmatamentos e queimadas}

De acordo com a matéria divulgada pela Amazônia Real (2021) as maiores taxas de desmatamento da última década na Amazônia foram registradas no ano de 2019. Mas 2020 pode ser ainda pior devido à pandemia. Um estudo do Instituto de Pesquisa Ambiental da Amazônia (IPAM) indica que há uma área desmatada de pelo menos 4.500 quilômetros quadrados que pode ser em 2020. Quatro estados concentram $88 \%$ dessa área: Pará (com 42\%) dos 4,5 mil km2, Mato Grosso (23\%), Rondônia (13\%) e Amazonas (10\%). O estudo relata que se tudo virar fumaça, a região pode enfrentar estado de calamidade pública na saúde devido a sobreposição de queimadas com pandemia de Covid-19, o que sobrecarregará ainda mais a rede saúde já em colapso nos atendimentos à população. (in site, AMAZÔNIA REAL, 2021).

Durante a temporada de fogo, extensas áreas da Amazônia têm qualidade do ar pior que no centro da cidade de São Paulo devido às queimadas. Isso tem forte efeito na saúde, especialmente em crianças e idosos, que são as populações mais vulneráveis. Como a poluição das queimadas viaja por milhares de quilômetros, comunidades isoladas de índios respiram esta atmosfera insalubre, que é muito acima dos padrões de qualidade do ar da Organização Mundial da Saúde.

Pesquisadores alertam para a possibilidade de um "desastre" nos sistemas de saúde se os desmatamentos e as queimadas não forem controlados a tempo. Pelos cálculos dos cientistas, se o ritmo acelerado de desmatamento continuar nos próximos meses, um total de quase 9 mil quilômetros quadrados poderá virar cinzas (Figura 13), já que a época mais intensa de derrubada e queima se inicia com a chegada do período seco na região. 


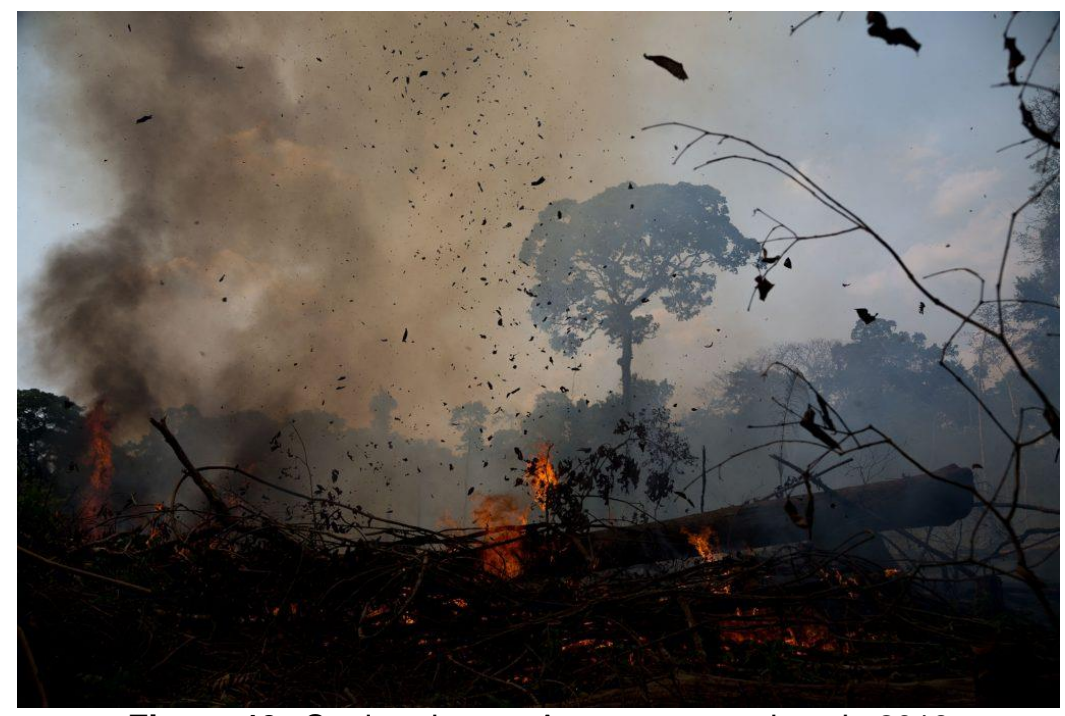

Figura 13: Queimadas no Acre em setembro de 2019

Fonte: Katie Maehler / Mídia NINJA) [CC-BY-NC]

Os focos de calor, que são os dados capturados por satélite, já ultrapassam os registrados em 2019 , no estado do Acre. É visto que ocorreram 61 focos de queimadas, ante 44 no mesmo período de 2019 - um aumento de $38 \%$. Pelos dados oficiais, o Acre registrou 6.802 focos de queimadas no ano 2019. No mesmo ano, o número de queimadas urbanas foi de 6.867 , segundo o Corpo de Bombeiros.

$\mathrm{Na}$ atualidade, existe uma dificuldade em analisar o que é mais difícil, se, o controle das queimadas (Figura 14) ou da pandemia. Todos os anos passa-se por dificuldades, mas a população continua realizando queimadas, citado pelo porta-voz do Corpo de Bombeiros do Acre, major Cláudio Falcão. "Infelizmente, temos registrados um aumento de queimadas urbanas e rurais. E isso faz com que o sistema de saúde se sobrecarregue ainda mais porque começam a aparecer doenças respiratórias. Vamos ter um problema muito sério", prevê Falcão. Embora já exista um plano de contingência em curso, a pandemia fez com que ações presenciais e preventivas fossem retraídas por conta das restrições do isolamento social. "É preciso conscientização da população e intensificação dos órgãos de fiscalização para podermos diminuir essa situação" (AMAZÔNIA REAL, 2021). 


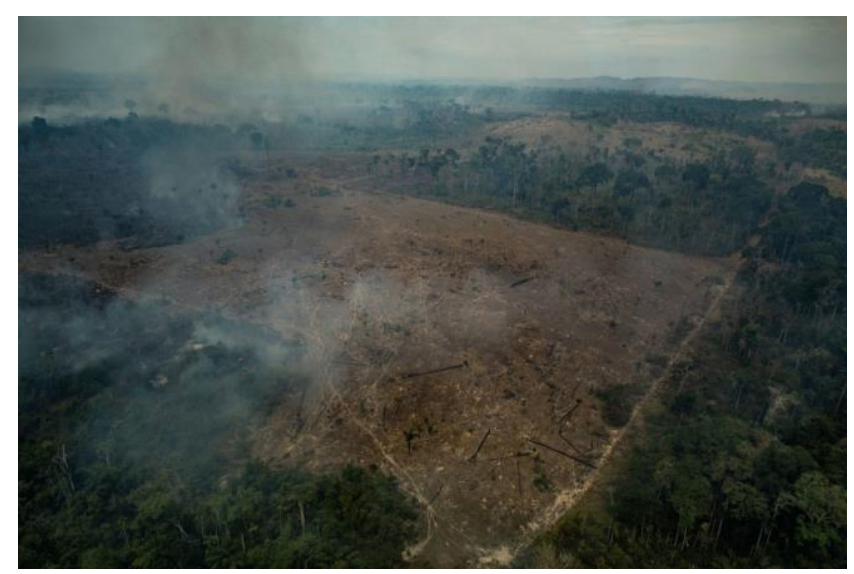

Figura 14: A lógica destrutiva das queimadas

Queimadas no Parna Jamanxim, em Novo Progresso, no Pará, em 24 de agosto de 2019

Fonte: Victor Moriyama/Greenpeace

Na história da destruição florestal na Amazônia, após o desmatamento (Figura 15) acontece uma queimada. Assim, sempre que a taxa de desmatamento cresce na Amazônia, há uma relação direta com o aumento de focos de calor. Os 4.500 quilômetros quadrados apontados pelo IPAM equivalem a três vezes a área da cidade de São Paulo. As queimadas aumentam a quantidade de fumaça no ar, transportando material particulado fino, os chamados aerossóis. Nas áreas mais atingidas pelas nuvens poluidoras, há uma explosão de pacientes que procuram o atendimento médico com agravamento de doenças respiratórias. No entanto, desde março (2020), os sistemas de saúde estão sobrecarregados com os casos de Covid-19, e três estados da Amazônia estão entre os que registram o maior número de casos da doença no Brasil (AMAZÔNIA REAL, 2021).

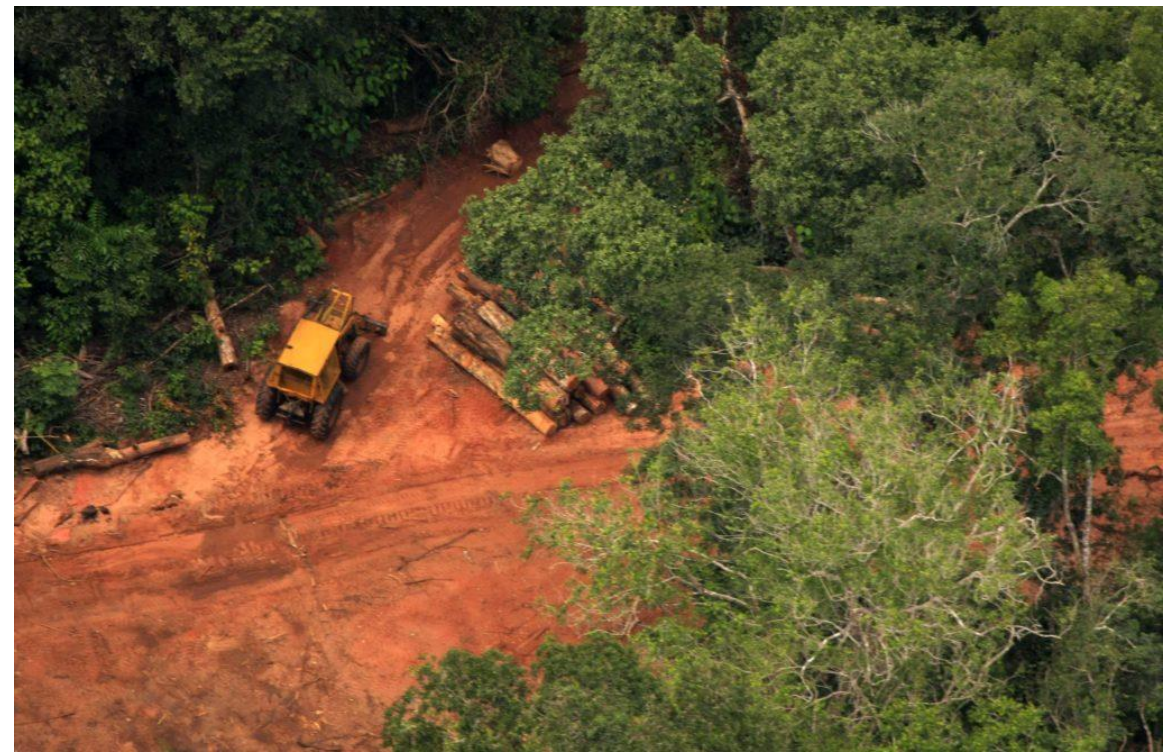

Figura 15: Desmatamento ilegal. Trator em área de desmatamento ilegal em São Félix do Xingu, no Pará, em 2012

Fonte: Alberto César Araújo/Amazônia Real 
Segundo o estudo, até o final de maio de 2020, o Brasil contabilizava 29.314 óbitos, sendo que $20 \%$ destes ocorreram na região Norte, que também registra a maior taxa de incidência $(584,6)$ e de mortalidade $(30,9)$ por 100 mil habitantes e, na época, contava com 107.752 casos confirmados, ou $20 \%$ do total nacional.

No Amazonas, no Pará e em Mato Grosso, mais de $20 \%$ das pessoas moram em áreas que exigem um deslocamento de até quatro horas para chegar ao município mais próximo com condições de atendimento em casos graves de Covid-19. As pequenas e médias cidades, se atingidas simultaneamente por fumaça das queimadas e infecções pelo novo coronavírus, tendem a não conseguir absorver a necessidade da população, diz a nota técnica.

No Pará, há um arco de fogo que liga a região de Altamira e São Félix do Xingu (Figura 16), com destaque para as terras indígenas Itauna-Itatá, Apiterewa e Trincheira-Bacajá, e mais a Área de Proteção Ambiental (APA) Triunfo do Xingu. O estudo aponta como áreas mais críticas a região ao longo da rodovia Transamazônica (BR-230) de Altamira a Rurópolis, com destaque para a Terra Indígena Cachoeira Seca, também faz parte das áreas críticas apontadas pelo IPAM, assim como Novo Progresso e Castelo dos Sonhos, com destaque para Floresta Nacional Jamanxim, e o Baixo Amazonas.

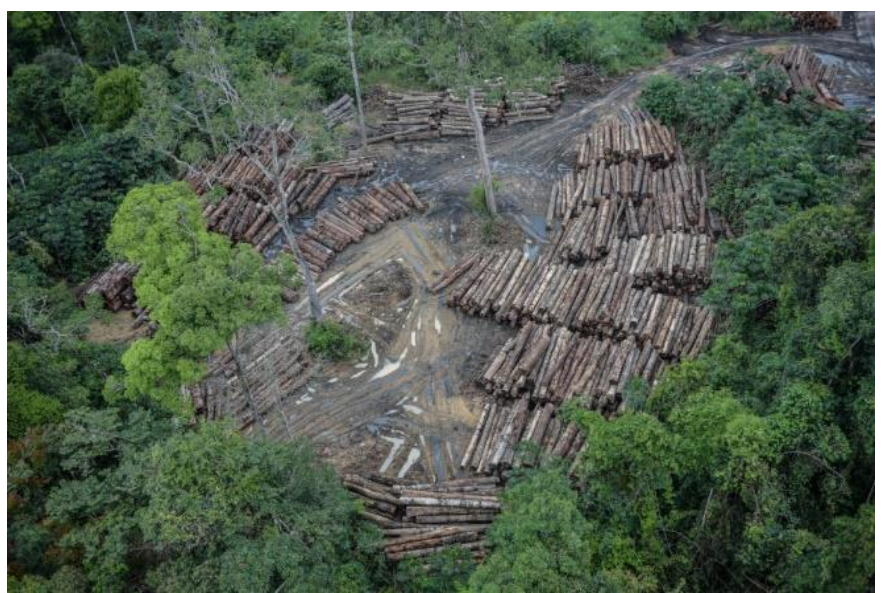

Figura 16: Alta no desmatamento. Desmatamento na TI Pirititi, em 2019

Fonte: Ibama

O Instituto Nacional de Pesquisas Espaciais (INPE) divulgou a taxa de desmatamento do Prodes, que apontou uma alta de $34,4 \%$ na devastação da Floresta Amazônica entre o período de agosto de 2018 e julho de 2019 em comparação ao mesmo período de 2017 e 2018. Foram desmatados 10.129 quilômetros quadrados - a maior taxa desde o ano de 2008, que foi de 12.911 quilômetros quadrados (AMAZÔNIA REAL, 2021). 


\section{Conclusão}

$\mathrm{Na}$ região amazônica, quando os europeus chegaram, no início do século XVI, até meados de 1950, a ocupação e o transporte de passageiros e carga ocorriam totalmente pelos rios. O Brasil possui atualmente $63 \mathrm{mil}$ quilômetros de extensão total de águas, $40.000 \mathrm{~km}$ são de rios, lagos e lagoas potencialmente navegáveis, destas pouco mais de $44 \%$ são utilizadas. Ao todo são nove grandes bacias, sendo a maior delas, a Amazônia, com $18.300 \mathrm{~km}$ de rios potencialmente navegáveis.

Uma análise das secas amazônicas, mostra que elas foram associadas a uma estação chuvosa deficiente durante o verão. A seca hidrológica é a mais impactante na fauna e flora dos ecossistemas aquáticos e de terra firme em áreas úmidas, e na população.

No entanto, seus impactos se intensificaram durante o período de estiagem, como também no período de pandemia. Favorecidos pelas condições secas que ocorrem durante o período de estiagem, os incêndios florestais da Amazônia, assim como os níveis de emissão de carbono, tendem a ser excessivamente altos.

As características peculiares da região Amazônica, a atual capacidade instalada do setor produtivo da região norte e as distâncias dos grandes centros produtores do país, tornam complexas a execução das funções logísticas, a coibição das queimadas e desmatamento nessa região, principalmente em período de pandemia Covid-19, o que exige das Organizações Militares de Apoio Logístico do Comando do 4ํㅡㄹ Distrito Naval iniciativa e criatividade, bem como a parceria com as demais forças singulares e Órgãos Federais, para superar os desafios da Região Amazônica, a fim de contribuir para salvaguarda dos interesses nacionais.

\section{Referências}

ALFREDINI, P. et.al. Engenharia Portuária. São Paulo. Blucher, 2014.

AMAZÔNIA REAL. Queimadas e pandemia projetam cenário de desastre na Amazônia. Disponível em < http://amazonia.org.br/2020/06/queimadas-epandemia-projetam-cenario-de-desastre-na-amazonia-diz-ipam/s Acesso em 27 de janeiro de 2021.

AMAZÔNIA AZUL. Disponível em <https://youtu.be/RtPHONuqQwE>. Acesso em 27 de janeiro de 2021.

BECKER, B.; STENNER, C. Um futuro para a Amazônia. São Paulo. Oficina de Textos, 2008.

BORMA, L.S. Secas na Amazônia. São Paulo. Oficina de Textos, 2013.

FRANÇA, J.L; VASCONCELOS, A.C. Manual para normalização de publicações técnico-científicas. Belo Horizonte. Editora UFMG, 2009. 
GONÇALVES, C.W.P. Amazônia, Amazônias. São Paulo. Contexto, 2010.

MARTINS, G.A.; THEÓPHILO, C.R. Metodologia da Investigação Científica para Ciências Sociais Aplicadas. Editora Atlas S.A., 2007.

MARINHA DO BRASIL. Flotilha do Amazonas. Disponível em: https://www.marinha.mil.br/comflotam/> Acesso em 27 de janeiro de 2021.

MARINHA DO BRASIL. Grupamento de Patrulha Naval do Norte. Disponível em <https://pt.wikipedia.org/wiki/Grupamento de Patrulha Naval do Norte> Acesso em 27 de janeiro de 2021.

NAPLOG. Navios de apoio logístico. Apresentado em 11 de outubro de 2017. Disponível em <https://youtu.be/iGEtmUFuegc> Acesso em 27 de janeiro de 2021.

NAVIOS PATRULHA. Da Marinha do Brasil. Apresentado em 11 de agosto de 2018. Disponível em <https://youtu.be/ZQwfQnHGgwE> Acesso em 27 de janeiro de 2021.

POLETO, C. Bacias Hidrográficas e recursos hídricos. Rio de Janeiro. 1 ed. Interciência, 2014.

PORTO DO ITAQUI. Disponível em <http://www.portodoitaqui.ma.gov.br/> Acesso em 27 de janeiro de 2021.

PORTOS E TERMINAIS. Disponível em <https://www.cdp.com.br/porto-debelem $>$ Acesso em 27 de janeiro de 2021.

SARACENI, P.P. Transporte Marítimo de Petróleo e derivados. Rio de Janeiro. 2 ed. Editora Interciência, 2012.

SIQUEIRA, I.P. Redes de infraestruturas críticas. Rio de Janeiro. Editora Interciência, 2014.

SOPESP. Brasil desperdiça $\mathbf{4 4} \mathbf{m i l} \mathbf{~ k m}$ de rios que poderiam ser utilizados para transporte. Disponível em <https://sopesp.com.br/2019/10/03/brasildesperdica-44-mil-km-de-rios-que-poderiam-ser-utilizados-para-transporte/> Acesso em 26 de janeiro de 2021.

STOPFORD, M. Economia Marítima. Tradução Dra. Ana Cristina Paixão Casaca [et.al.] São Paulo. Blucher, 2017. 